\title{
Configuration Effects on Liner Performance
}

\author{
Carl H. Gerhold ${ }^{1}$, Martha C. Brown ${ }^{2}$, Michael G. Jones ${ }^{3}$, Brian M. Howerton ${ }^{4}$ \\ NASA Langley Research Center, Hampton, Virginia, 23681
}

The acoustic performance of a duct liner depends not only on the intrinsic properties of the liner but also on the configuration of the duct in which it is used. A series of experiments is performed in the NASA Langley Research Center Curved Duct Test Rig (at Mach 0.275) to evaluate the effect of duct configuration on the acoustic performance of single degree of freedom perforate-over-honeycomb liners. The liners form the sidewalls of the duct's test section. Variations of duct configuration include: asymmetric (liner on one side and hard wall opposite) and symmetric (liner on both sides) wall treatment; inlet and exhaust orientation, in which the sound propagates either against or with the flow; and straight and curved flow path. The effect that duct configuration has on the overall acoustic performance, particularly the shift in frequency and magnitude of peak attenuation, is quantified. The redistribution of incident mode content is shown. The liners constitute the side walls of the liner test section and the scatter of incident horizontal order 1 mode by the asymmetric treatment and order 2 mode by the symmetric treatment into order 0 mode is shown. Scatter of order 0 incident modes into higher order modes is also shown. This redistribution of mode content is significant because it indicates that the liner design can be manipulated such that energy is scattered into more highly attenuated modes, thus enhancing liner performance.

\section{Introduction}

Despite significant strides that have led to aircraft engine noise reduction, notably the high bypass ratio engine, the engine is still the dominant aircraft noise source in most flight regimes. The acoustic treatment most commonly used to control engine noise, both in inlet and exhaust ducts, is the locally reacting liner. Such a liner typically consists of a perforated sheet over a honeycomb core. This is backed by a solid sheet to form an array of Helmholtz resonators that resonate at a fixed frequency, both absorbing engine noise and reflecting it back toward the source to inhibit noise radiation toward the ground. The liner's intrinsic properties; honeycomb depth, perforate thickness, number and size of holes in the perforate; determine the impedance of the liner assembly. The environment in which it is used determines the acoustic performance. Liners add mass and induce drag, affecting fuel consumption. The economic considerations favor minimizing the amount of liner while noise control considerations favor increased liner coverage. In order to extract the most acoustic energy with the least size and weight, the liner design must be tailored for the specific engine environment.

Considerations of the engine acoustic environment include sound pressure level and frequency as well as modal content and flow. Motsinger and $\mathrm{Kraft}^{1}$ discuss the effects of boundary layer refraction in liner design. In the inlet, the sound wave propagates against the flow and the boundary layer tends to refract waves toward the axis of the duct. This decreases the propagation angle and effectively converts the waves into lower order radial modes. In the exhaust, where sound propagation is with the flow, the boundary layer refracts waves toward the wall, increasing the propagation angle and thus increasing the absorption by the liner. Mani ${ }^{2}$ notes that convective effects are also a consideration and liner efficiency is a compromise between refractive and convective effects. Convection slows the wave speed in the inlet to increase the time the wave is over the liner and it increases the speed in the exhaust to decrease the wave's exposure time. Mani asserts that the interaction between convective and refractive effects is felt more strongly in the inlet than in the exhaust. Flow path curvature is often a consequence of the engine design but it has an impact on sound propagation. Previous research ${ }^{3,4}$ has demonstrated that curvature redistributes the modal content of the incident sound.

Experimental rigs have been developed to simulate engine noise generation conditions and to assess the performance of acoustic treatments. Chestnutt and Lansing ${ }^{5}$ investigated several inlet noise reduction concepts,

\footnotetext{
1 Senior Research Scientist, Research Directorate, Aeroacoustics Branch, Associate Fellow, AIAA

2 Aerospace Engineer, Research Directorate, Aeroacoustics Branch

${ }^{3}$ Senior Research Scientist, Research Directorate, Structural Acoustics Branch, Associate Fellow, AIAA

${ }^{4}$ Aerospace Engineer, Research Directorate, Structural Acoustics Branch, Senior Member, AIAA
} 
including sonic inlet, hybrid (sonic and lined) inlet, inlets with various liner patches, and a refracting inlet. While the designs showed promise for noise control, the degradation of fan performance limited their applicability. Motsinger, et al. ${ }^{6}$ showed that a 2 -stage liner could be more effective than an optimized 1-stage liner. The first stage is used to redistribute mode energy from the incident wave into higher order modes that are well attenuated by the second stage. The Curved Duct Test Rig (CDTR) is an experimental facility that has been developed for the purpose of evaluating acoustic liners in an environment approximating an engine duct. The flow path is on the order of 25$100 \%$ of engine scale, flow speeds to Mach 0.50 can be achieved, flow path curvature up to 1 duct dimension offset can be accommodated, and modal content of the incident sound can be controlled. The experiments discussed in the current paper were conducted in the CDTR at flow speed of Mach 0.275. The effect on acoustic performance of design characteristics including symmetry of duct treatment, direction of flow, and flow path curvature were investigated using plane waves and waves of higher order modes incident on the liner section. The effect that duct configuration has on overall attenuation is determined, particularly the shift in frequency and magnitude of peak attenuation. The effect that duct configuration has on mode redistribution is of particular note. It is shown that the mode redistribution can be controlled by the liner design. This is significant because if the liner can redistribute energy into modes that are more readily attenuated, the overall efficiency of the liner treatment is enhanced.

\section{Description of the Experiment}

\section{Test Facility}

The CDTR is an open loop wind tunnel that uses a fan to draw unconditioned atmospheric air through the test section, as shown in Figure 1. The flow delivery system consists of an inlet bellmouth in a shed to prevent debris/water ingestion, a $152.4 \mathrm{~cm} \times 76.2 \mathrm{~cm}$ vertical duct, a $90^{\circ}$ bend with a $1.14 \mathrm{~m}$ average radius, and a $152.4 \mathrm{~cm}$ x $76.2 \mathrm{~cm}$ to $76.2 \mathrm{~cm} \times 76.2 \mathrm{~cm}$ transition (transition 1). Downstream of the transition is the test section, which consists of a flow conditioning section with screens and honeycomb, transition to $15.2 \mathrm{~cm} \times 37.7 \mathrm{~cm}$ duct, loudspeaker section, upstream microphone section, liner sample section, downstream microphone section, and diffuser/anechoic termination. Downstream of the test section is a transition to a $99.1 \mathrm{~cm} \times 99.1 \mathrm{~cm}$ duct (transition 2), resonator, muffler, and the fan. The fan is a centrifugal fan rated at $1416 \mathrm{~m}^{3} / \mathrm{min}$ and driven by a $447 \mathrm{~kW}$ motor. The muffler reduces fan noise in the test section in the audible frequencies, above $500 \mathrm{~Hz}$. The resonator was designed as a reactive muffler, to reflect the low frequency fan noise in the range from 63 to $500 \mathrm{~Hz}$ back toward the fan, thereby reducing the amount of fan noise impinging on the test section. While sound is not measured below 400 $\mathrm{Hz}$, the fan noise driving the microphones reduces their effective dynamic range, and their sensitivity is improved by reducing the fan noise in the low frequencies. The muffler and resonator are designed to reduce the fan-generated noise to $10 \mathrm{~dB}$ below the expected flow noise in the test section at Mach 0.50 .

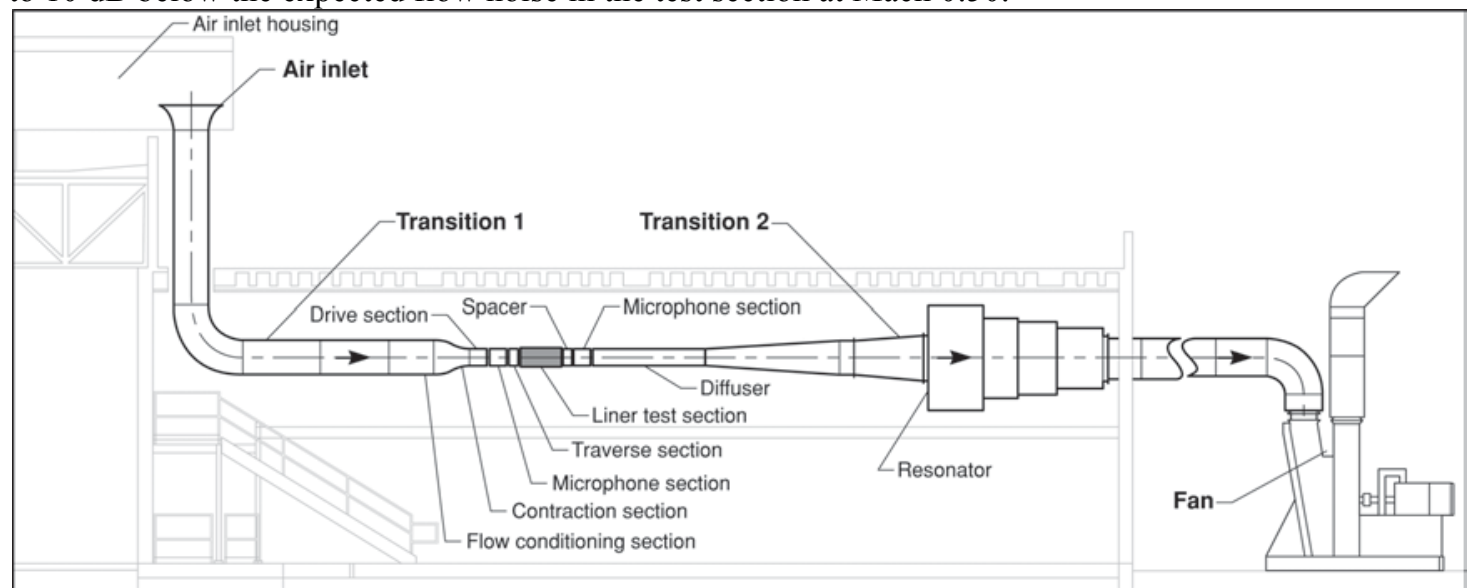

Figure 1. Drawing of the Curved Duct Test Rig layout in the Liner Technology Facility.

Figure 2 shows a representation of the test section of the CDTR. In the figure, flow is from left to right. The figure shows the loudspeaker source section, the upstream microphone section, the liner sample section, and the downstream microphone section. The duct is shown in 'exhaust' orientation with the source section upstream of the upstream microphones. The construction of the CDTR is modular, so that the loudspeaker section can be installed downstream of the downstream microphones to achieve the 'inlet' orientation. Sound in the duct is generated by an array of 16 loudspeakers. The magnitude and phase of the voltage signal to each loudspeaker is controlled such that 
a selected mode can be generated in the duct. A subset of the upstream microphone array is used as the control to adjust the signals to the loudspeakers. The microphone and loudspeaker arrays and the sound control system are described in a previous paper? The recorded signals from the upstream and downstream microphone arrays are analyzed to determine the mode distribution of the sound in the duct incident upon and discharged from the liner sample section, as discussed in previous papers ${ }^{4,7}$. The control system is designed not only to generate a selected mode but also to suppress all other modes in the duct. Thus, the sound incident on the liner is predominantly composed of the selected mode, which is at least $10 \mathrm{~dB}$ greater than any other mode in the duct. This was demonstrated previously by the authors ${ }^{8}$.

The full array of microphones is used to determine the modal amplitudes of the sound waves entering and leaving the liner test section. The sound power in each mode is calculated ${ }^{4}$ and summed for the total sound power. The attenuation is the difference between the sound power level entering the liner test section and the sound power exiting the liner test section.

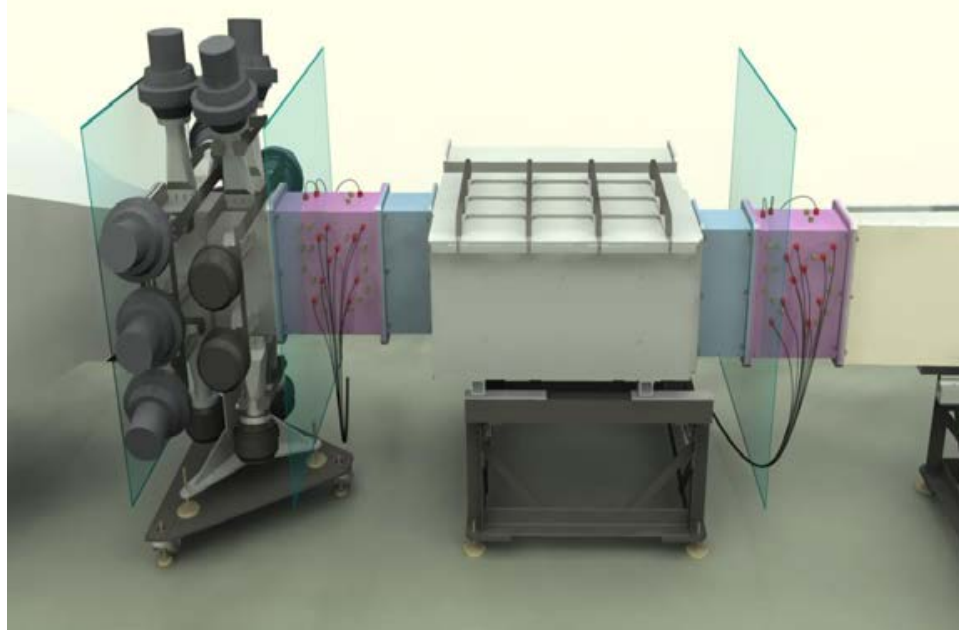

Figure 2. Representation of CDTR test section in 'exhaust' orientation. Flow is from left to right.

\section{Test Set-up}

Each of the liners used in these experiments consists of $19.1 \mathrm{~mm}$ deep honeycomb core covered by 1.01 $\mathrm{mm}$ thick perforated plate. The plate is $8.7 \%$ open area and the holes in the plate are $1.01 \mathrm{~mm}$ diameter. The liner materials are representative of single degree of freedom liners in use in engines and the liner is designed for operation in the presence of Mach 0.3 to 0.5 flow. The resonance frequency of the liner installed in the CDTR occurs in the middle of the operating range of the CDTR, between 300 and $2400 \mathrm{~Hz}$. The liner samples are $38.1 \mathrm{~cm}$ high by approximately $81.3 \mathrm{~cm}$ long in the flow direction. Liner samples are tested in the CDTR, where they form the side wall(s) of the flow duct. The flow path is $38.1 \mathrm{~cm}$ high by $15.2 \mathrm{~cm}$ wide. All tests reported here were performed with the flow speed set at Mach 0.275.

The liner described above for use in the straight flow path is given the designation L02 and the different duct configurations are described as follows. The asymmetric duct treatment with the liner L02 on the right hand wall and the hard wall opposite is designated L02RE for the 'exhaust' orientation and L02RI for the 'inlet' orientation. The symmetric duct treatment with the L02 liner on both walls of the duct is designated L02SE for the 'exhaust' orientation of operation and L02SI for the 'inlet' orientation. The liner sample section can also be configured with the flow path offset from the entrance to the discharge of the liner test section. The liner with offset of 6 inches between the inflow and outflow flanges is designated L04. The curvature of the liners is designed such that the slope increases linearly from zero at the inlet to a maximum at the mid point and then decreases linearly from the midpoint to the discharge, where the slope is zero. The asymmetric duct treatment with the liner L04 on the right hand wall and the hard wall opposite is designated L04RE for the 'exhaust' orientation and L04RI for the 'inlet' orientation. The symmetric duct treatment with the L04 liner on both walls of the duct is designated L04SE for the 'exhaust' orientation and L04SI for the 'inlet' orientation. Table I summarizes the test duct configurations. 
TABLE I. Summary of duct configurations evaluated.

\begin{tabular}{|c|c|c|c|c|c|c|}
\hline Designation & \multicolumn{2}{|c|}{ Orientation } & \multicolumn{2}{c|}{ Liner symmetry } & \multicolumn{2}{c|}{ Curvature } \\
\hline & 'inlet' & 'exhaust' & 1 side & Both & Straight & 1-D offset \\
\hline L02RE & & $\mathrm{X}$ & $\mathrm{X}$ & & $\mathrm{X}$ & \\
\hline L02RI & $\mathrm{X}$ & & $\mathrm{X}$ & & $\mathrm{X}$ & \\
\hline L02SE & & $\mathrm{X}$ & & $\mathrm{X}$ & $\mathrm{X}$ & \\
\hline L02SI & $\mathrm{X}$ & & & $\mathrm{X}$ & $\mathrm{X}$ & \\
\hline L04RE & & $\mathrm{X}$ & $\mathrm{X}$ & & & $\mathrm{X}$ \\
\hline L04RI & $\mathrm{X}$ & & $\mathrm{X}$ & & & $\mathrm{X}$ \\
\hline L04SE & & $\mathrm{X}$ & & $\mathrm{X}$ & & $\mathrm{X}$ \\
\hline L04SI & $\mathrm{X}$ & & & $\mathrm{X}$ & & $\mathrm{X}$ \\
\hline
\end{tabular}

Figure 3 shows the liner sample section with the straight liner installed on both walls, the symmetric case. The asymmetric treatment case is achieved by substituting the liner on the left side of the duct with a wall sample in which the perforate has been replaced by a solid sheet.

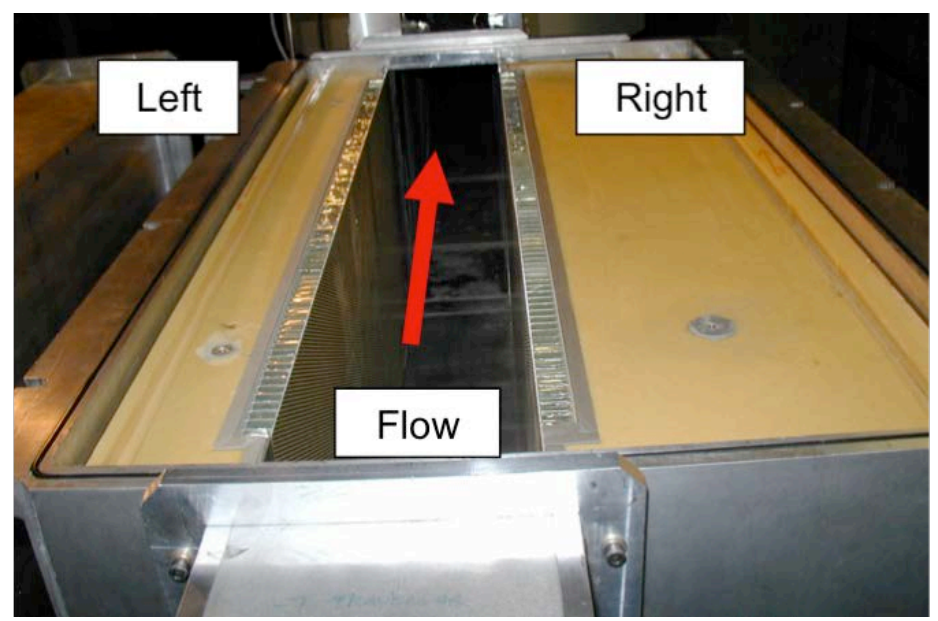

Figure 3. Liner sample section with straight liner samples on both walls, top removed, view looking downstream.

The sound wave incident on the liner test section consists of a tone generated in the duct at $130 \mathrm{~dB}$. The wave is controlled to have either symmetric (horizontal order 0 and 2) or asymmetric (horizontal order 1) modeshape in combination with up to 5 vertical order. The modes are designated as (Vertical, Horizontal) throughout the report.

\section{Results}

\section{Frequency of peak attenuation}

Jones, et al. ${ }^{9}$ use a Two Parameter Impedance Prediction model to define the impedance parameters, the resistance and reactance, of a single-degree-of-freedom perforate over honeycomb core liner. The expression for impedance, normalized by the characteristic impedance, $\rho c$, is given as:

$$
\frac{Z}{\rho c}=\zeta=\theta(d, t, M)+i \chi(f, t, d, h)
$$

The resistance term, $\theta$, is defined by the thickness of the perforated facesheet, $\mathrm{t}$, the hole diameter, $\mathrm{d}$, and the Mach number of the grazing flow in the duct, $\mathrm{M}$. The reactance, $\chi$, depends on the perforate thickness and hole diameter, the core depth of the honeycomb, $h$, and the frequency, $\mathrm{f}$. The reactance component of the impedance 
consists of a mass reactance, which varies linearly with frequency and a transmission line with rigid termination, which varies as $-\cot (k h)$.

A liner sample fabricated with the same perforate and honeycomb, but with core depth of $38.2 \mathrm{~mm}$ was evaluated in the Grazing Incidence Tube by Jones, et al. ${ }^{10}$, and the impedance was educed using $130 \mathrm{~dB}$ incident sound and Mach 0.30 centerline flow velocity. It is assumed that the difference in Mach number is negligible and that the impedance of the liner sample L02 can be derived from the educed impedance using the formula:

$$
\zeta_{19.1}=\theta_{38.2}+i\left[\chi_{38.2}+\cot \left(k h_{38.2}\right)-\cot \left(k h_{19.1}\right)\right]
$$

The assumptions implicit in this relationship are that the resistance and the mass reactance are the same for the liner irrespective of the honeycomb depth, and the transmission portion of reactance is adjusted by the term involving the honeycomb core depth. With that correction, the educed impedance of the liner L02, for flow at Mach 0.275, is shown in Figure 4. The resistance is designated $\mathrm{R}(\mathrm{edu})$ and the reactance is designated $\mathrm{X}(\mathrm{edu})$.

The optimum impedance of a liner for $(0,0)$ mode incident on a channel of height $\mathrm{H}$ with liners on both sides at no flow was first derived by Cremer ${ }^{11}$, and later revised in Beranek ${ }^{12}$ and $\mathrm{Kraft}^{13}$. The values are slightly different among the authors, and the expression used by Kraft is:

$$
\left(\zeta_{\text {opt } 0}\right)_{0}=(0.93-0.74 i) \eta
$$

where:

$\eta=H / \lambda$

When the duct is lined on one side only, the optimum impedance is determined using twice the duct height, because the hard wall acts as the midline axis of symmetry of a duct of height $2 \mathrm{H}$ that lined on both sides. The equations for optimum impedance do not include the effect of flow path curvature, nor do they indicate any frequency shift at different vertical mode order.

Tester ${ }^{14}$ modified the expression to include flow:

$\zeta_{o p t M}=\frac{\zeta_{o p t 0}}{(1+M)^{2}}$

In the 'exhaust' orientation, the flow and incident sound propagate in the same direction and the Mach number is positive in Equation 4. When the duct is operated in 'inlet' orientation, the incident sound propagates opposite the flow and the Mach number is negative in Equation 4.

When the input mode is of horizontal order 1, the expression used by Kraft for no flow is:

$$
\left(\zeta_{\text {opt } 0}\right)_{1}=(0.67-0.34 i) \eta
$$

The optimum resistance, $\mathrm{R}(\mathrm{opt})$ and reactance, $\mathrm{X}$ (opt) for the duct with a liner on one side and a hard wall on the opposite side, operated in the 'exhaust' mode at Mach 0.275, are plotted on the educed impedance curve in Figure 4. In the nomenclature adopted above, this is liner configuration designated L02RE. The optimum reactance intersects the educed reactance at $2035 \mathrm{~Hz}$. Thus, it is expected that the peak of the attenuation curve for the liner designated L02RE should occur in the vicinity of $2035 \mathrm{~Hz}$, but not exactly because the educed resistance does not coincide with the optimum at $2035 \mathrm{~Hz}$.

The expected frequencies of peak attenuation for the various operating conditions and for the 0 order and 1 order horizontal modes are tabulated in Table II. The table shows the liner description, the horizontal mode order $(0$ or 1), the optimum reactance, the frequency at which the measured reactance equals the optimum $\left(\mathrm{F}_{\mathrm{opt}}\right)$, the frequency at which the peak attenuation is measured ( $\mathrm{F}_{\text {meas }}$ as will be shown later), and the optimum and educed resistance at $\mathrm{F}_{\mathrm{opt}}$. It is assumed that the liner impedance is the same for all configurations at Mach 0.275.

While the measured frequencies of peak attenuation are not the same as the expected frequencies from the optimum, they are within $15 \%$, and they trend the same way. That is, the frequency of peak attenuation is lower for the 'inlet' orientation than for the 'exhaust', and the peak frequency for the symmetric treatment (both walls lined) is 
higher than the peak frequency for asymmetric treatment (one wall lined). No peak frequency was measured for horizontal order 1 modes incident on the asymmetric liner for either exhaust or inlet. For the exhaust, that could be because the peak is outside the measured frequency range $(400-2400 \mathrm{~Hz})$. It is not clear why the 'inlet' orientation did not produce a measurable peak in the attenuation curve.

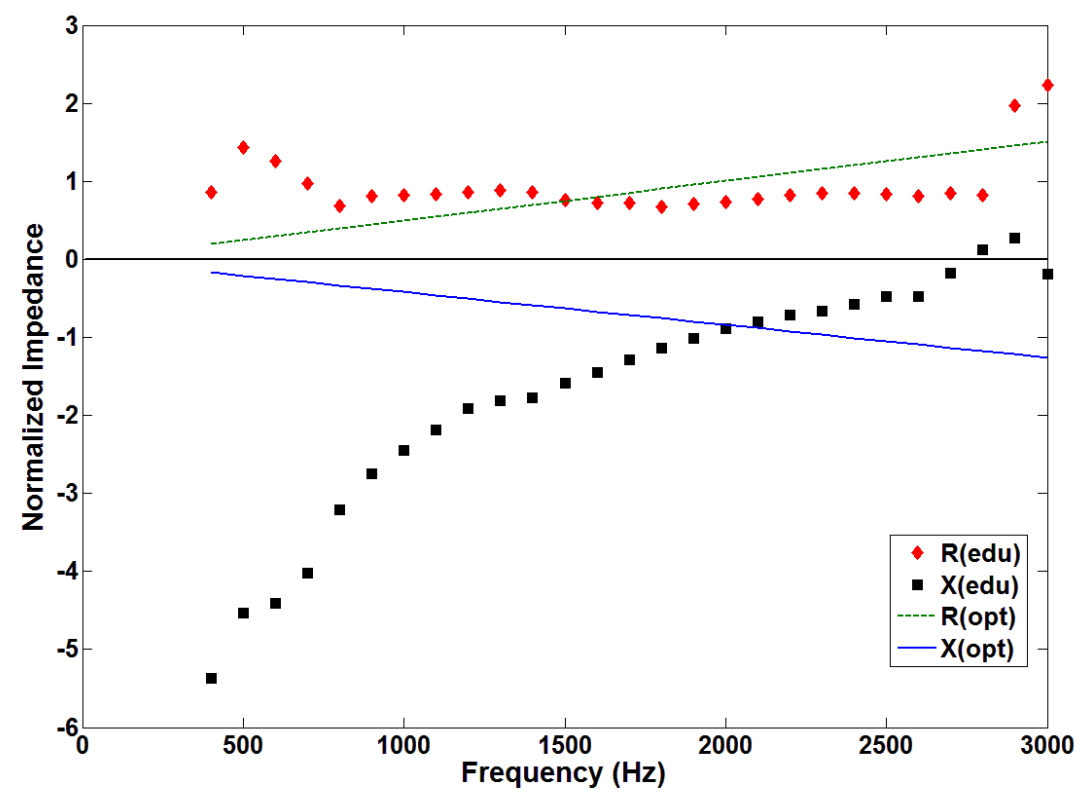

Figure 4. Plot of normalized impedance for liner $\mathrm{LO2}$ at Mach 0.275. Plot shows resistance, R(edu), and reactance, $X(e d u)$, educed from measurements in the Grazing Incidence Tube; and the resistance, $R(o p t)$, and reactance $\mathrm{X}(\mathrm{opt})$ for liner on one side in 'exhaust' orientation, corresponding to L02RE.

Table II. Estimated from optimum and observed frequency of peak attenuation for incident horizontal mode order in CDTR, Mach 0.275.

\begin{tabular}{|c|c|c|c|c|c|c|}
\hline ID & $\begin{array}{c}\text { Horiz } \\
\text { mode }\end{array}$ & $\begin{array}{c}\text { optimum } \\
\text { Reactance }\end{array}$ & $\mathrm{F}_{\text {opt }}$ & $\mathrm{F}_{\text {meas }}$ & \multicolumn{2}{|c|}{ Resistance } \\
\cline { 5 - 7 } & 0 & -0.855 & 2035 & 1800 & optimum & educed \\
\hline L02RE & 0 & -1.780 & 1371 & 1200 & 2.012 & 0.746 \\
\hline L02RI & 0 & -0.517 & 2462 & 2200 & 0.618 & 0.863 \\
\hline L02SE & 0 & -1.160 & 1786 & 1800 & 1.385 & 0.680 \\
\hline L02SI & 1 & -0.481 & 2593 & - & 0.948 & 0.810 \\
\hline L02RE & 1 & -1.065 & 1858 & - & 2.100 & 0.691 \\
\hline L02RI & 1 & -0.248 & 2678 & 2300 & 0.489 & 0.842 \\
\hline L02SE & 1 & -0.660 & 2302 & 2000 & 1.301 & 0.843 \\
\hline L02SI & 1 & \multicolumn{2}{l}{} \\
\hline
\end{tabular}

\section{Effect of symmetry of liner treatment}

A series of experiments was performed in which the attenuation of tonal sound was measured with the duct configured for straight flow path with asymmetric liner treatment, one wall lined and the opposite wall acoustically hard; and with symmetric treatment, identical liners on both sides of the duct. The duct was in the 'exhaust' mode. These duct configurations are designated L02RE and L02SE, respectively.

Figure 5 shows the overall attenuation measured with the $(0,0)$ mode incident on the liner sample section in the 'exhaust' orientation. The frequency of peak attenuation for the symmetric wall treatment, L02SE, is $2200 \mathrm{~Hz}$ and it shifts down to $1800 \mathrm{~Hz}$ when the treatment is asymmetric. This is comparable to the expected values of peak attenuation frequency of $2462 \mathrm{~Hz}$ and $2035 \mathrm{~Hz}$, respectively, from Table II. It is felt that the measured values are different from the expected because the optimum resistance does not intersect the educed resistance at the same frequency as the corresponding reactance. 


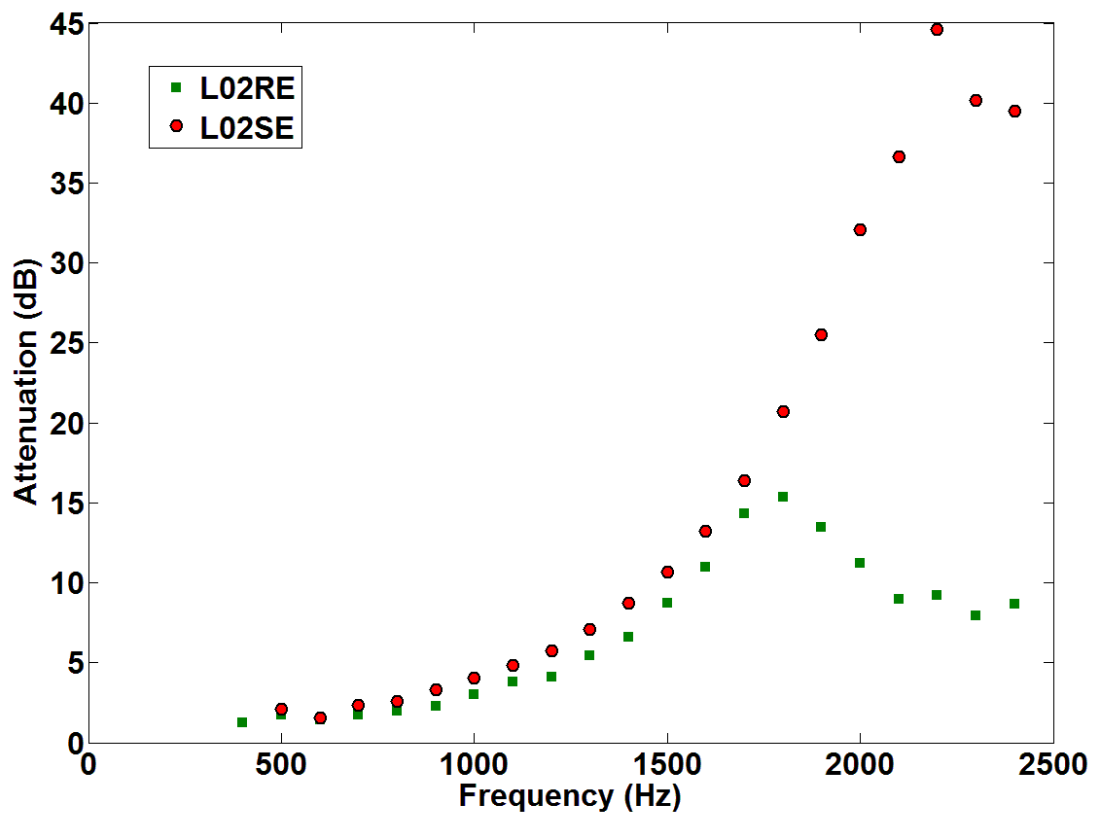

Figure 5. Overall attenuation with duct in 'exhaust' orientation, Mach $0.275,(0,0)$ mode incident. Compares symmetric liner treatment L02SE with asymmetric treatment L02RE.

The symmetric liner would be expected to provide twice the attenuation of the asymmetric liner, yet the peak attenuation of L02RE is on the order of $1 / 3$ the peak attenuation of L02SE. One reason for this discrepancy is seen in the mode decomposition of the sound downstream of L02RE with the $(0,0)$ mode incident, shown in Figure 6. It is not shown here, but the mode distribution of the sound upstream of the liner consists of the target mode $((0,0)$ in this case) at amplitude $130 \mathrm{~dB}+/-1 \mathrm{~dB}$ from 400 to $2100 \mathrm{~Hz}$. Also, the only mode that is amplified from upstream to downstream is the $(0,1)$ mode. The authors demonstrated previously ${ }^{4,8}$ that, since the energy of the wave incident on the liner is dominated by the target mode, the energy distribution after the liner is a good indicator both of energy removed from the target mode and of energy scattered into other modes. Figure 6 shows that the $(0,0)$ mode dominates downstream everywhere but at the frequency of peak attenuation. The amplitude of the $(0,0)$ mode is 105 $\mathrm{dB}$, indicating that the $(0,0)$ mode is attenuated by $\sim 25 \mathrm{~dB}$. However, energy is scattered from the $(0,0)$ mode into the higher order horizontal mode $(0,1)$, because of the asymmetry of the treatment, such that the $(0,1)$ mode dominates, reducing the overall attenuation at the peak to $15 \mathrm{~dB}$. Many more modes are cut-on in the duct than the two modes shown in Figure 6, but they do not contribute significantly to the overall sound and have been deleted from the figure for clarity. In this and subsequent mode decomposition plots, only the dominant modes will be shown.

The scatter of energy from the 0 order horizontal mode to the next order 1 horizontal mode occurs for higher vertical mode orders, as can be seen in Figure 7, in which the $(1,0)$ is input to L02RE. Energy scatters at the attenuation peak into the $(1,1)$ mode, however, the scatter is less than it was for $(0,0)$ mode input. In fact, the energy scatter continues to decrease at higher vertical mode orders so that the overall attenuation approaches $\sim 25 \mathrm{~dB}$. This is shown in Figure 8, where the attenuation of the first 5 vertical orders of 0 order horizontal mode are plotted. Note that the $(3,0)$ mode is barely cut-on at the frequency of peak attenuation and the $(4,0)$ mode cuts on after the peak. The attenuation of these two modes is much higher than for the lower order modes because of the reduced scatter combined with the fact that the sound near cut-on propagates more nearly normal to the liner making the absorption more efficient. This was also found in a previous study of a different design of single-degree-of-freedom liner by the authors 8 .

Figure 9 shows the mode decomposition for the $(0,0)$ mode incident on the symmetric liner, L02SE. The $(0,0)$ mode dominates up to $2100 \mathrm{~Hz}$ and scatters little energy into the $(0,2)$ mode at the frequency of peak attenuation.

When the $(0,1)$ mode is incident on the asymmetric liner, the peak attenuation is expected to occur at approximately $2600 \mathrm{~Hz}$, which is outside the frequency range of the test. Figure 10 shows the mode decomposition of the sound downstream of L02RE with the $(0,1)$ mode incident. It appears that the $(0,1)$ mode component is heading toward a minimum at the highest frequency measured, $2400 \mathrm{~Hz}$, but the frequency of peak attenuation is not 
clear. Note also that energy is scattering into the $(0,0)$ mode. This is consistent with the expectation that the liner scatters energy into a lower order, less-attenuated mode, as observed in a previous study ${ }^{14}$ of a different liner.

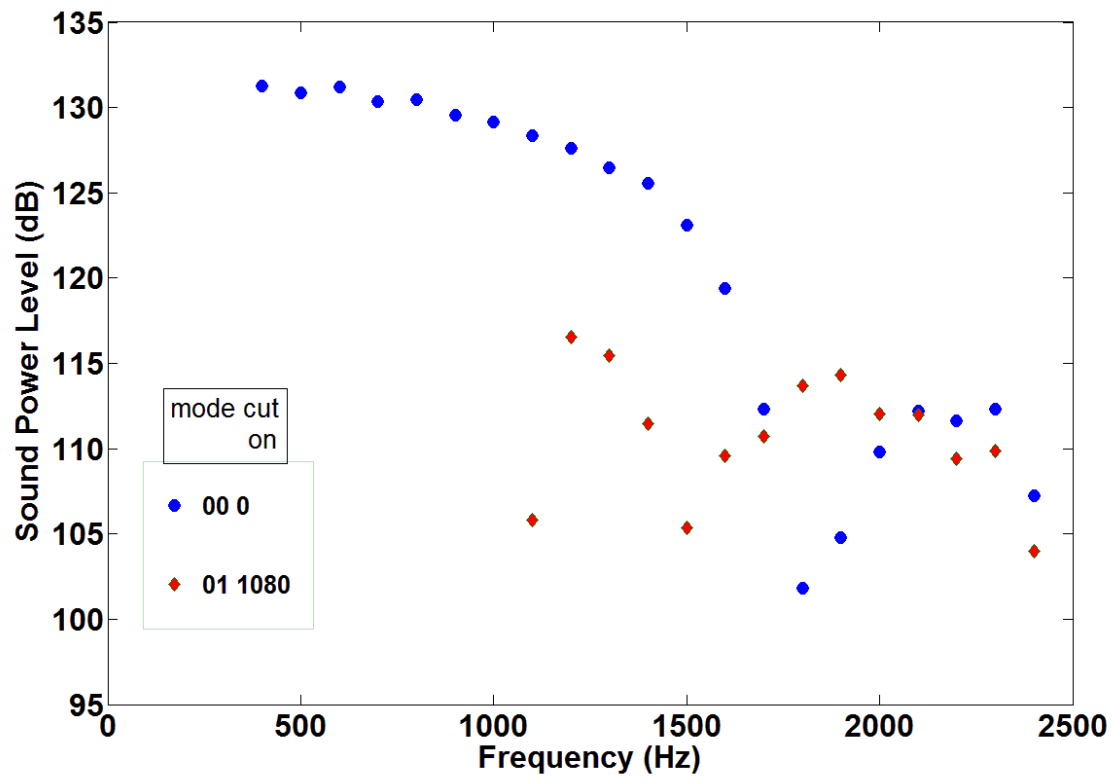

Figure 6. Mode distribution of sound power downstream of liner sample section in 'exhaust' orientation, asymmetric liner L02RE, for $(0,0)$ mode incident, Mach 0.275 .

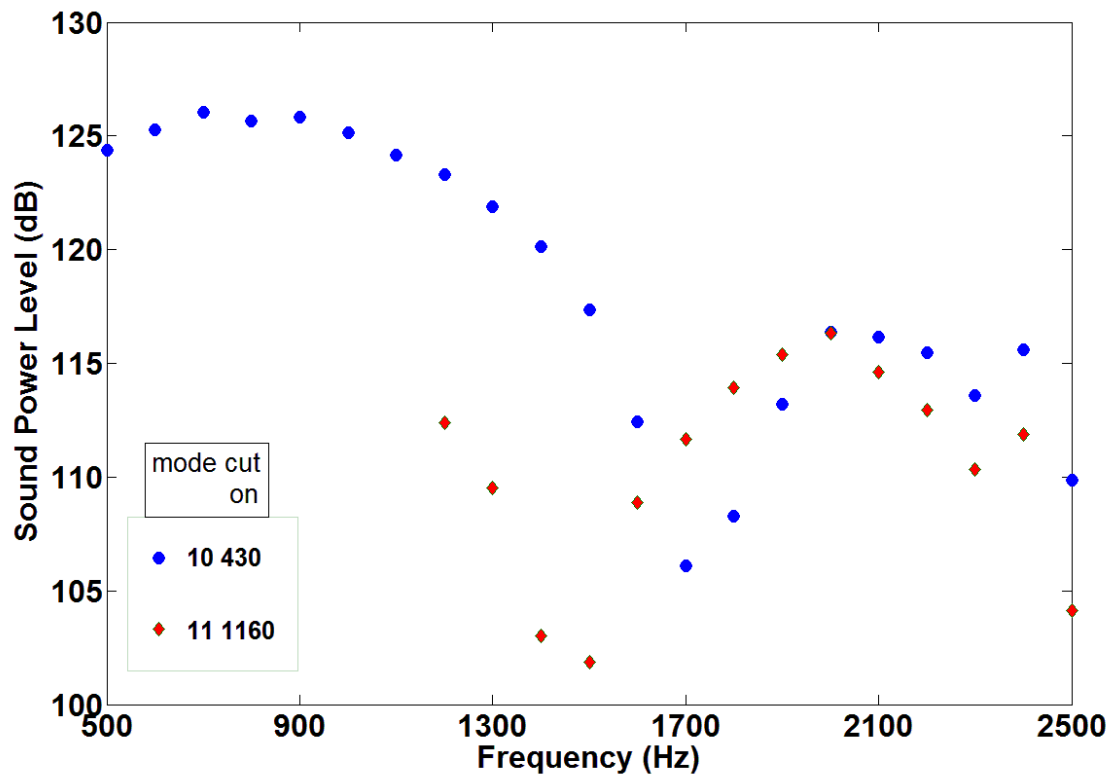

Figure 7. Mode distribution of sound power downstream of liner sample section in 'exhaust' orientation, asymmetric liner L02RE, for $(1,0)$ mode incident, Mach 0.275 . 


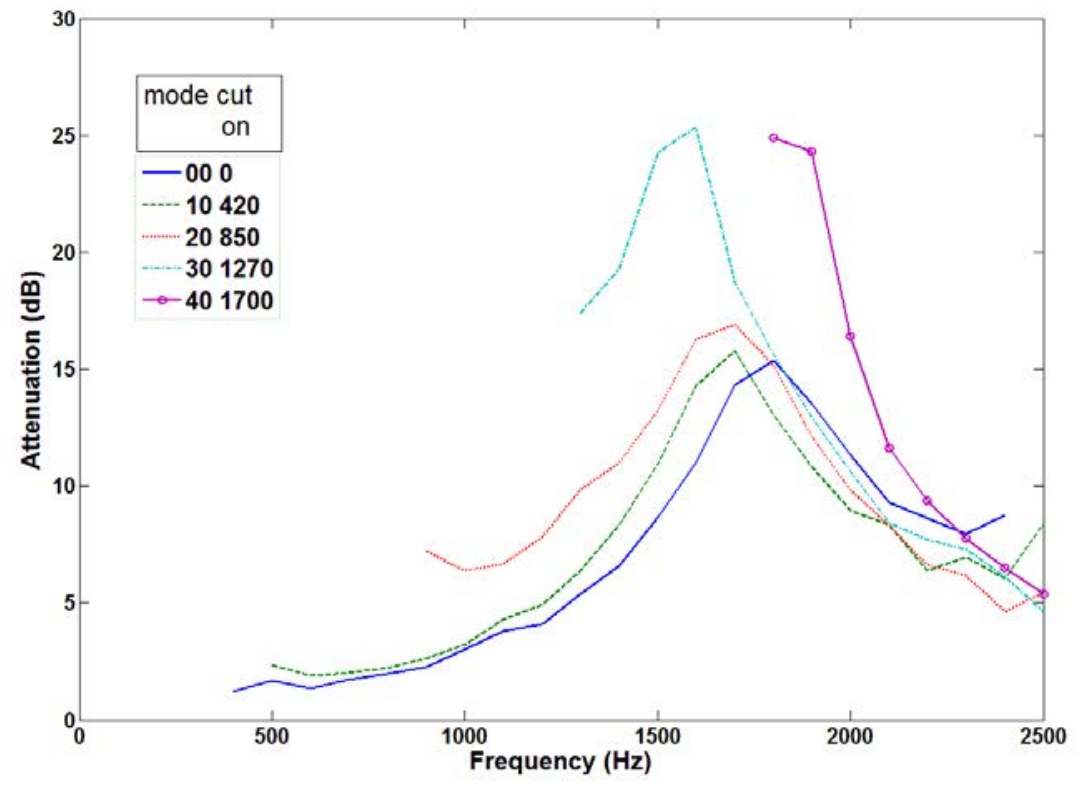

Figure 8. Overall attenuation of liner L02RE for various vertical orders of 0 horizontal order mode incident on the liner test section, Mach 0.275. Cut-on frequencies of the modes are shown in the key.

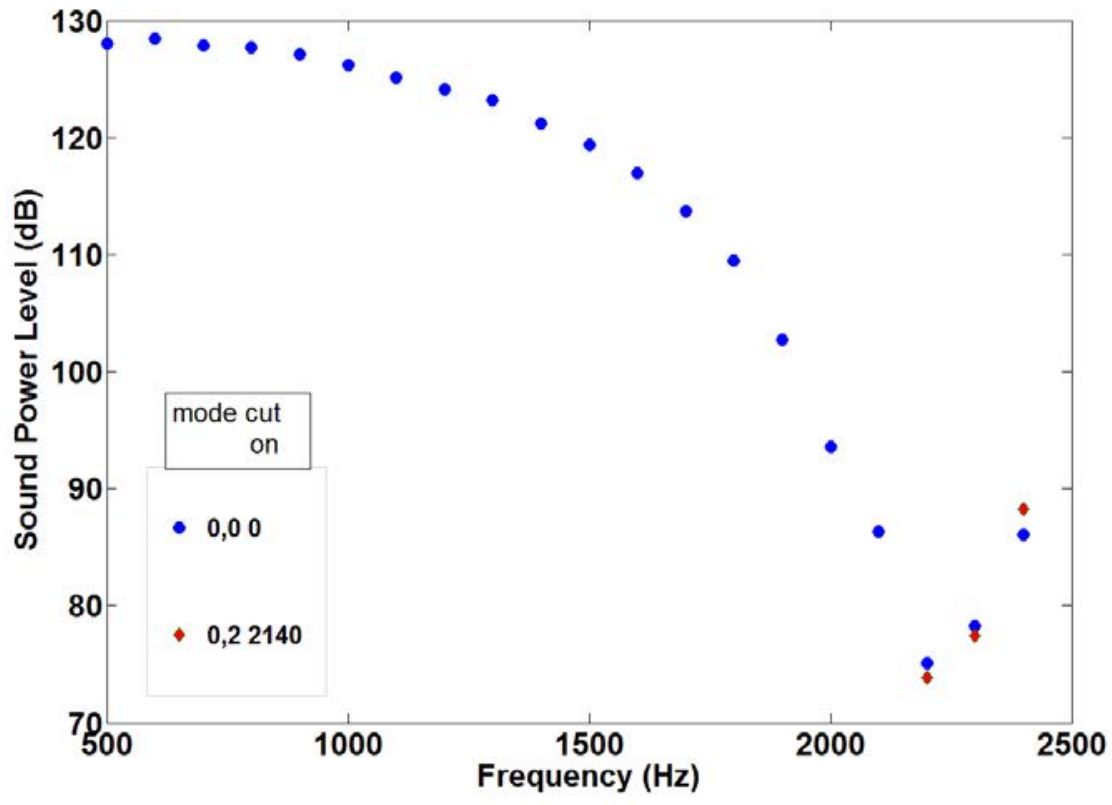

Figure 9. Mode distribution of sound power downstream of liner sample section in 'exhaust' orientation, symmetric liner L02SE, for $(0,0)$ mode incident, Mach 0.275 . 


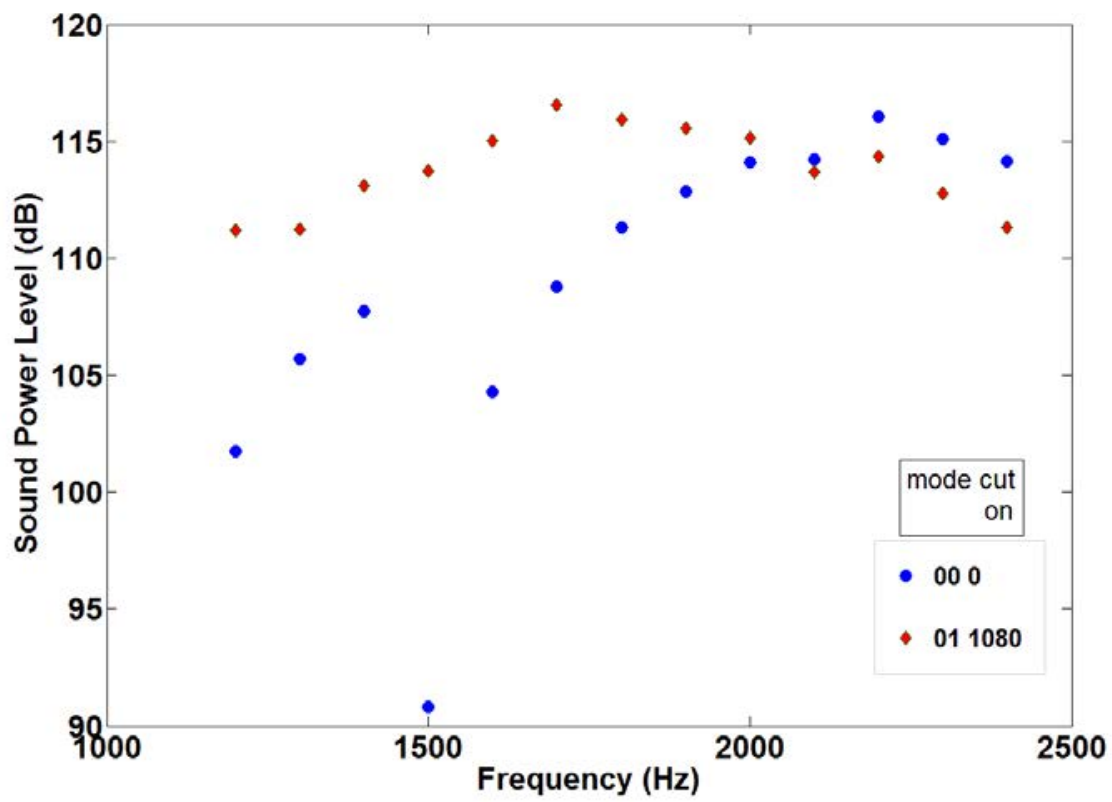

Figure 10. Mode distribution of sound power downstream of liner sample section in 'exhaust' orientation, asymmetric liner L02RE, for $(0,1)$ mode incident, Mach 0.275 .

\section{Effect of flow direction}

When the duct is in the 'inlet' orientation, with sound and flow traveling in opposite directions, the peak attenuation is expected to shift down in frequency. This can be seen from Table II and by comparing Figure 11 with Figure 5. Figure 11 shows the overall attenuation measured with the $(0,0)$ mode incident on the liner sample section in the 'inlet' orientation. The frequency of peak attenuation for the symmetric wall treatment, L02SI, is $1800 \mathrm{~Hz}$

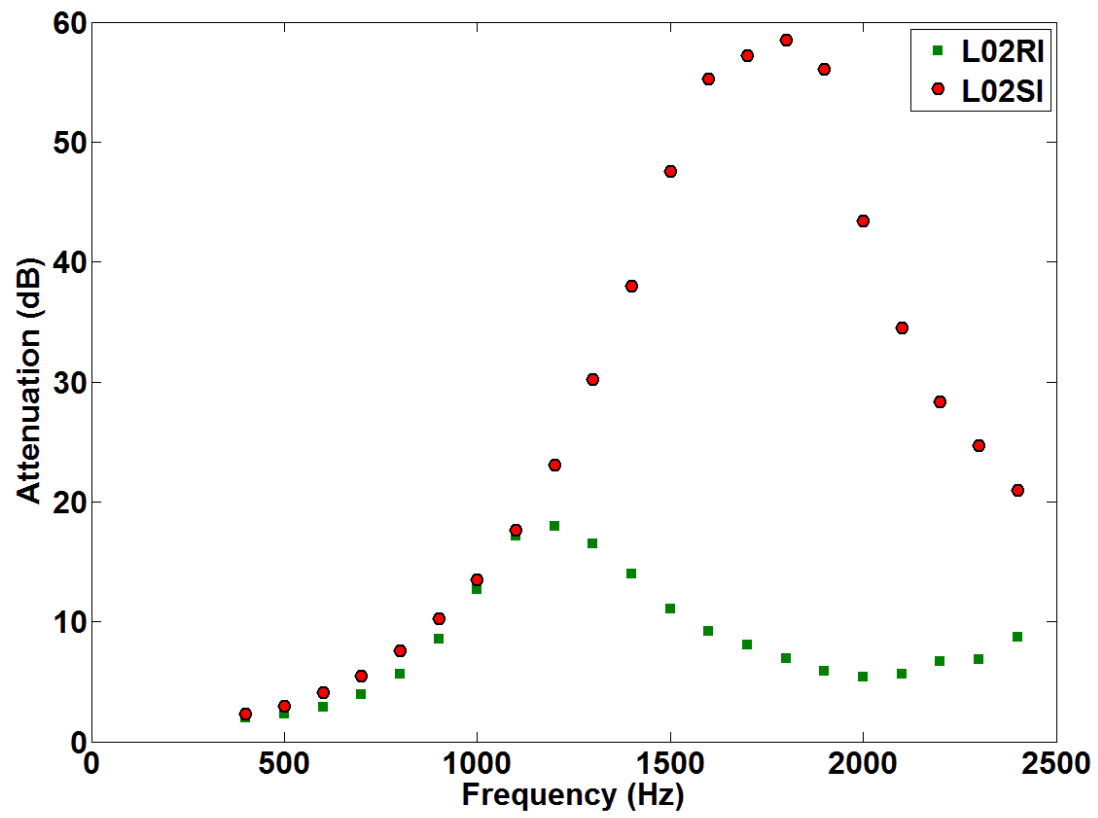

Figure 11. Overall attenuation with duct in 'inlet' orientation, Mach 0.275, (0,0) mode incident. Compares symmetric liner treatment L02SI with asymmetric treatment L02RI. 
where it was $2200 \mathrm{~Hz}$ for L02SE. The peak attenuation occurs at $1200 \mathrm{~Hz}$ when the treatment is asymmetric, L02RI, where in the 'exhaust', L02RE, it was $1800 \mathrm{~Hz}$. The frequency shift is consistent with the expected shift shown in Table II (Fopt).

The peak attenuations for the $(0,0)$ mode incident on the liner in the 'inlet' orientation are higher than they are for the 'exhaust'. The mode distribution, Figure 12, shows much less incident energy is scattered into the $(0,1)$ mode than was found for the 'exhaust' orientation, Figure 6. Interestingly, the attenuation of the $(0,0)$ mode in the 'exhaust' orientation appears to be $10 \mathrm{~dB}$ greater than the attenuation of the $(0,0)$ mode in the 'inlet' orientation, but because of mode scatter, overall attenuation with the $(0,0)$ mode incident is $5 \mathrm{~dB}$ greater in the 'inlet' orientation.

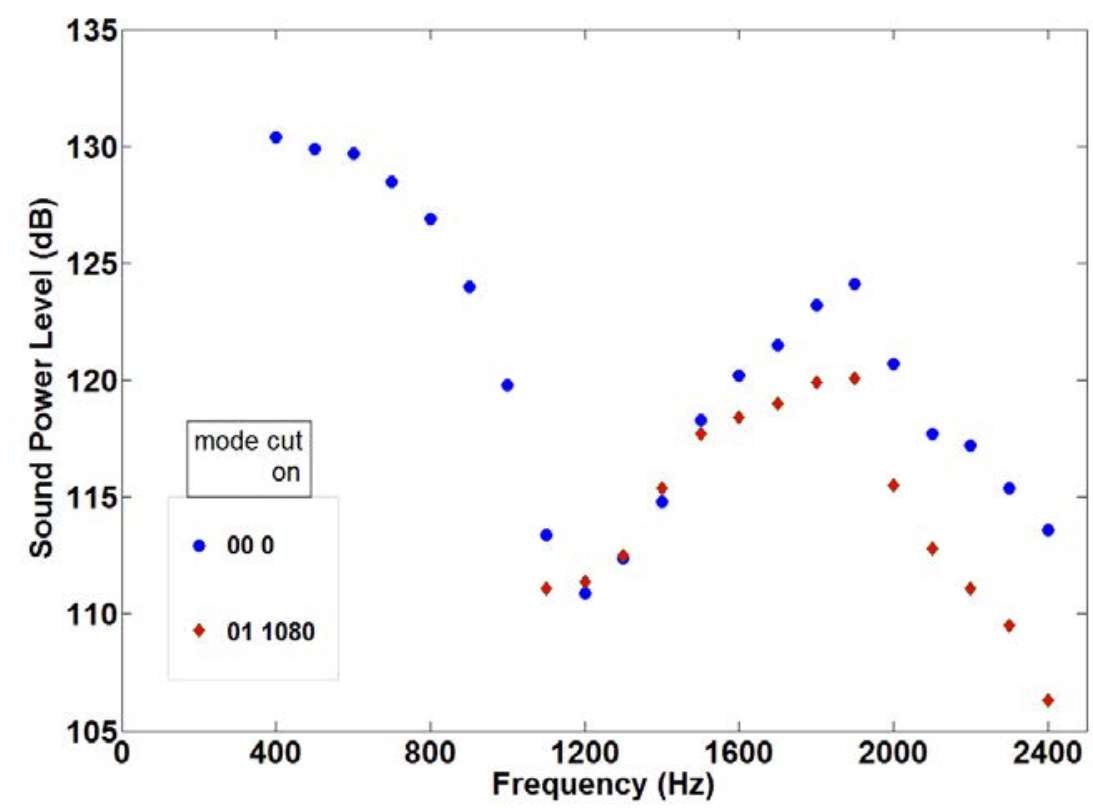

Figure 12. Mode distribution of sound power upstream of liner sample section in 'inlet' orientation, asymmetric liner L02RI, for $(0,0)$ mode incident, Mach 0.275.

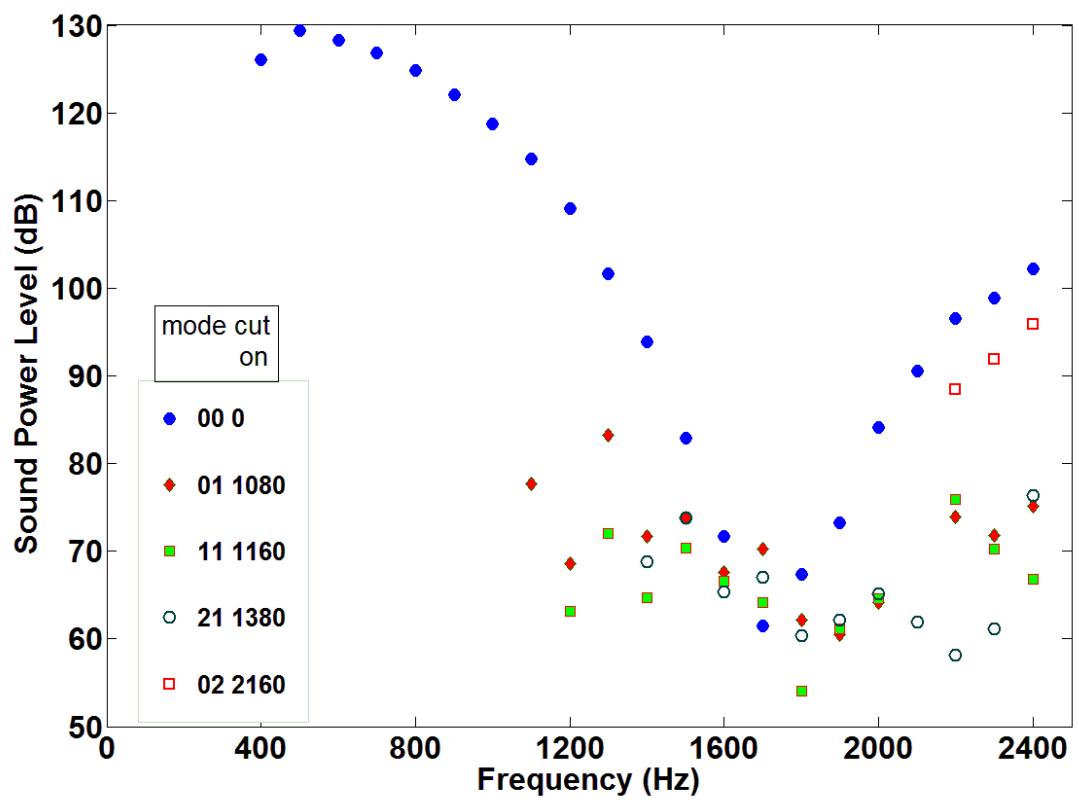

Figure 13. Mode distribution of sound power upstream of liner sample section in 'inlet' orientation, symmetric liner L02SI, for $(0,0)$ mode incident, Mach 0.275. 
Figure 13 shows that less energy is scattered from the $(0,0)$ mode into the higher order $(0,2)$ mode for the symmetric treatment case, L02SI because the attenuation peak occurs well below cut-on of the $(0,2)$ mode. In addition, the $(0,0)$ mode attenuation is approximately $12 \mathrm{~dB}$ greater in the 'inlet' orientation than the 'exhaust', Figure 9. The random distribution of modes shown in Figure 13 at the frequency of peak attenuation indicates that the noise floor of the tunnel has been reached.

Even though energy scatter into higher order modes is inhibited in the 'inlet' orientation, energy scatters efficiently into lower order modes. Figure 14 shows the mode distribution upstream of liner L02RI for the $(0,1)$ mode incident. The scatter of incident energy into the $(0,0)$ mode is evident throughout the frequency range.

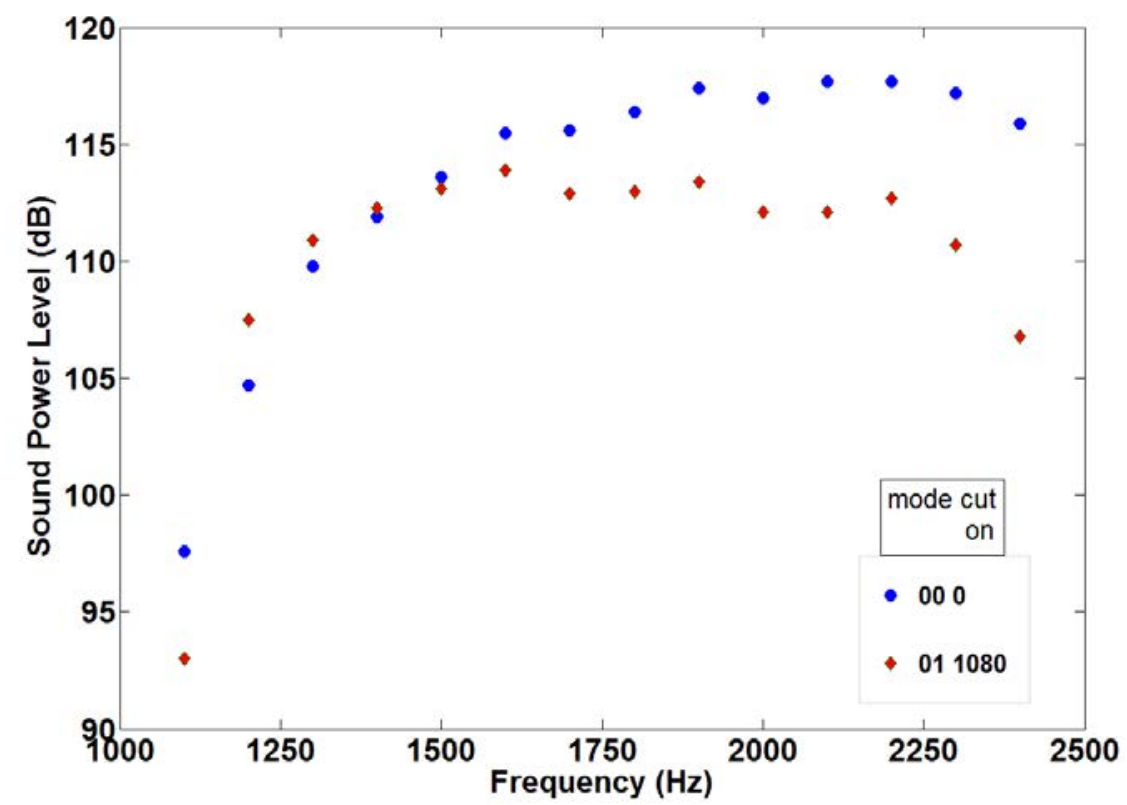

Figure 14. Mode distribution of sound power upstream of liner sample section in 'inlet' orientation, asymmetric liner L02RI, for $(0,1)$ mode incident, Mach 0.275 .

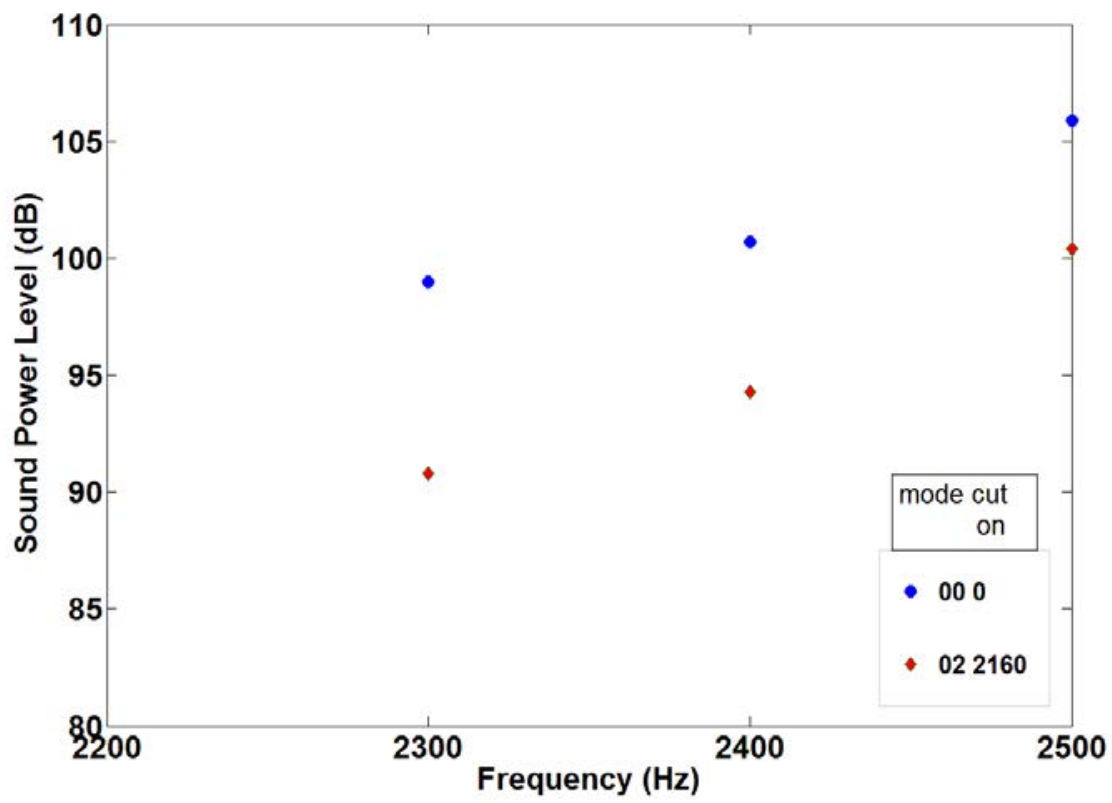

Figure 15. Mode distribution of sound power upstream of liner sample section in 'inlet' orientation, symmetric liner L02SI, for $(0,2)$ mode incident, Mach 0.275 . 
Similarly, energy scatters from the $(0,2)$ mode into the $(0,0)$ mode for all frequencies above the cut-on in the case of the symmetric treatment, L02SI. This is shown in Figure 15.

\section{Flow path curvature effect}

The Curved Duct Test Rig can accommodate liner samples for which the flow path is offset by as much as 1 duct width from inlet to exhaust. For this configuration, there is no direct line of sight through the liner test section. Figure 16 shows the CDTR with the flow path in the 1D-offset curvature.

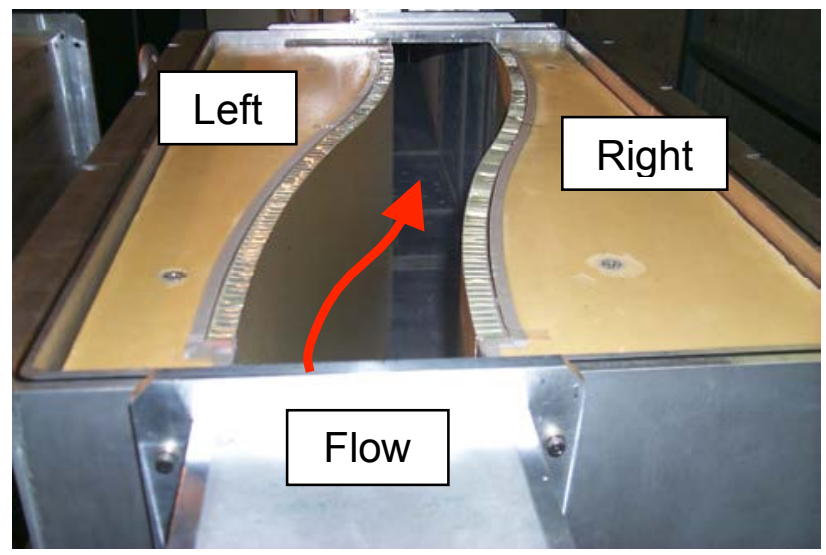

Figure 16. Curved Duct Test Rig configured with 1D-offset curvature.

The offset curvature was investigated in a previous paper by the authors ${ }^{15}$ with the duct in the 'exhaust' orientation only. It was found that when the treatment is symmetric, the attenuation with 1D-offset is approximately $2 \mathrm{~dB}$ greater than the straight duct at all frequencies except at the peak, where the two results are equal. This result is shown in Figure 17 (L02SE and L04SE) along with the comparison of 0-offset to 1D-offset for the 'inlet' orientation. In both instances the 0 -offset and $1 \mathrm{D}$-offset attenuations are generally within $2 \mathrm{~dB}$ of one another, indicating that this particular offset design does not affect the attenuation significantly whether 'inlet' or 'exhaust'.

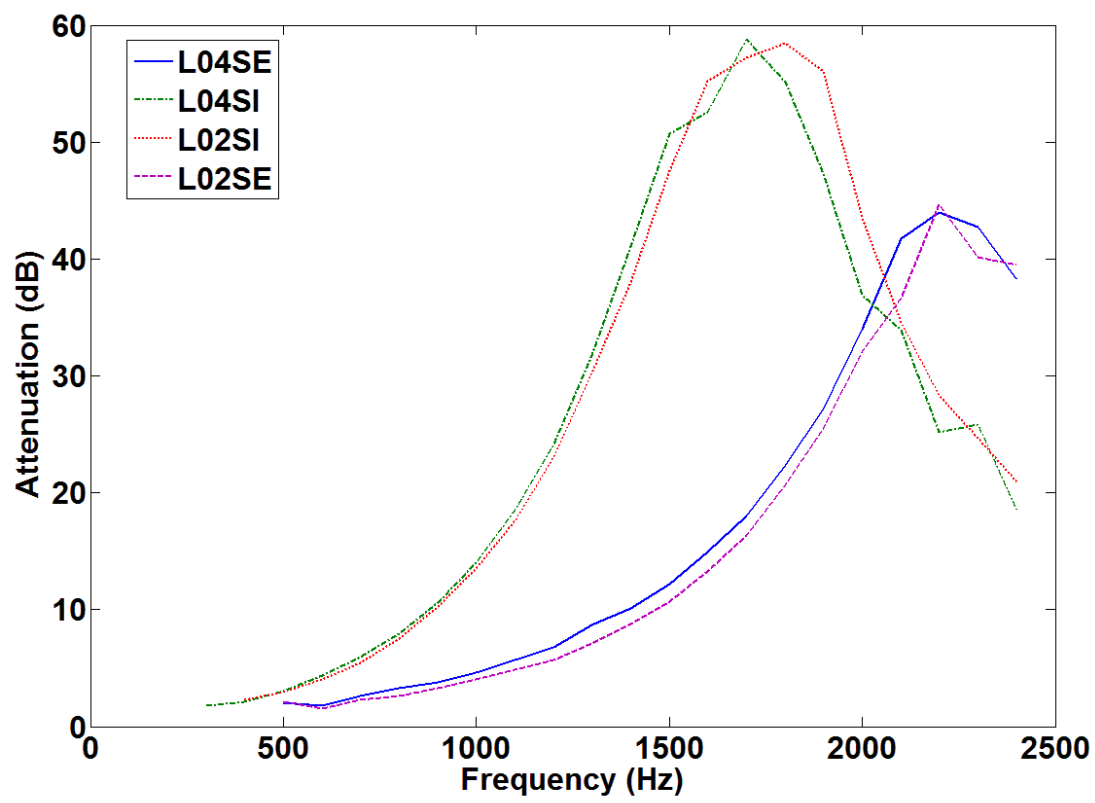

Figure 17. Overall attenuation of $(0,0)$ mode incident on liner at Mach 0.275 , liner on both sides, comparing 1D offset (L04S) to 0 offset (L02S). Results are shown for testing in 'exhaust' and 'inlet' orientations. 
For the asymmetric case in the previous paper ${ }^{15}$, only the $1 \mathrm{D}$ offset was analyzed but with liner treatment on the left wall compared to treatment on the right wall. Liner treatment on the left wall produced higher attenuation than with the treatment on the right wall, although the difference decreased with increasing vertical mode order. This difference was attributed to the orientation of the curvature. When the liner is on the left wall, the incoming wave encounters a lined bend, but when the liner is on the right wall the incoming wave encounters a solid wall bend. In the present paper, the asymmetric treatment is compared between 0-offset and 1D-offset in 'exhaust' and 'inlet' orientations.

Figure 18 shows the overall attenuation with the $(0,0)$ mode incident on the liner sample section with the liner on the right wall. In the figure, the 1D-offset results are compared with the 0 -offset results for the 'inlet' and 'exhaust' orientations. The results for 1D-offset are comparable to the 0-offset results in the 'inlet' orientation. In the 'exhaust' orientation, the 0-offset attenuation at the peak is approximately $6 \mathrm{~dB}$ higher than the peak attenuation for 1-D offset.

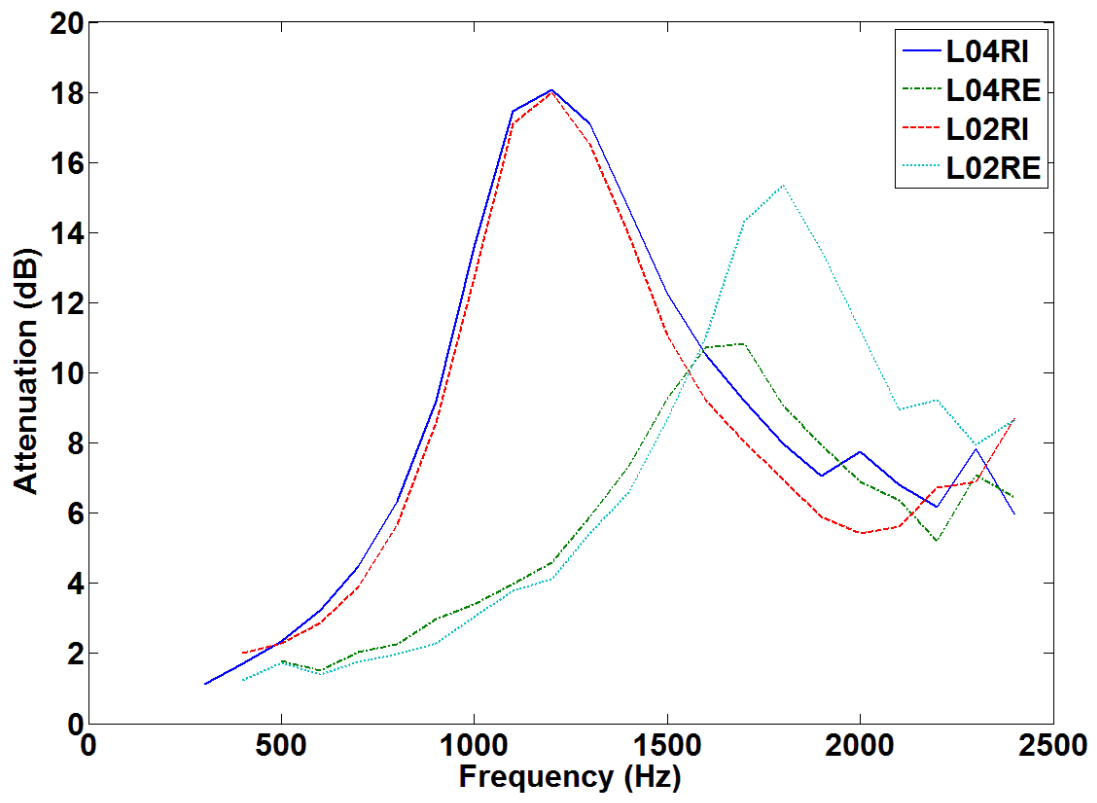

Figure 18. Overall attenuation of (0,0) mode incident on liner at Mach 0.275, comparing 1D offset (L04) to 0 offset (L02), one wall lined. Results are shown for testing in 'exhaust' and 'inlet' orientations.

The downward shift in frequency and increased peak attenuation from 'exhaust' to 'inlet' is expected from previous results. Curvature is not expected to change the attenuation dramatically, as is seen by comparing the 'inlet' cases L02RI and L04RI. However, the difference between 0-offset and 1D-offset in the 'exhaust' orientation is unexpected. Figure 19, shows the mode distribution downstream of the 1D-offset liner L04RE with the $(0,0)$ mode incident. The energy scatter into the $(0,1)$ mode is significant, more than was seen in the 0 -offset case, Figure 6 . It is felt that the scatter is enhanced by the curvature in the duct. The incoming wave encountering the bend "sees" a solid surface, which enhances the scatter.

As the vertical mode order increases, the difference between 0-offset and 1D-offset decreases for the 'exhaust' orientation, as can be seen in Figure 20 for $(2,0)$ mode incident. Thus, the scatter caused by the curvature decreases for higher order modes.

The results obtained in the present study are comparable to those obtained in the previous study ${ }^{15}$. When the liner treatment is symmetric, the difference between the 0-offset and 1D-offset attenuation is small. When the treatment is asymmetric and the incoming wave encounters a solid wall at the bend in the offset duct, the sound scatter is enhanced, and the overall attenuation decreases. The effect is less for higher order modes. 


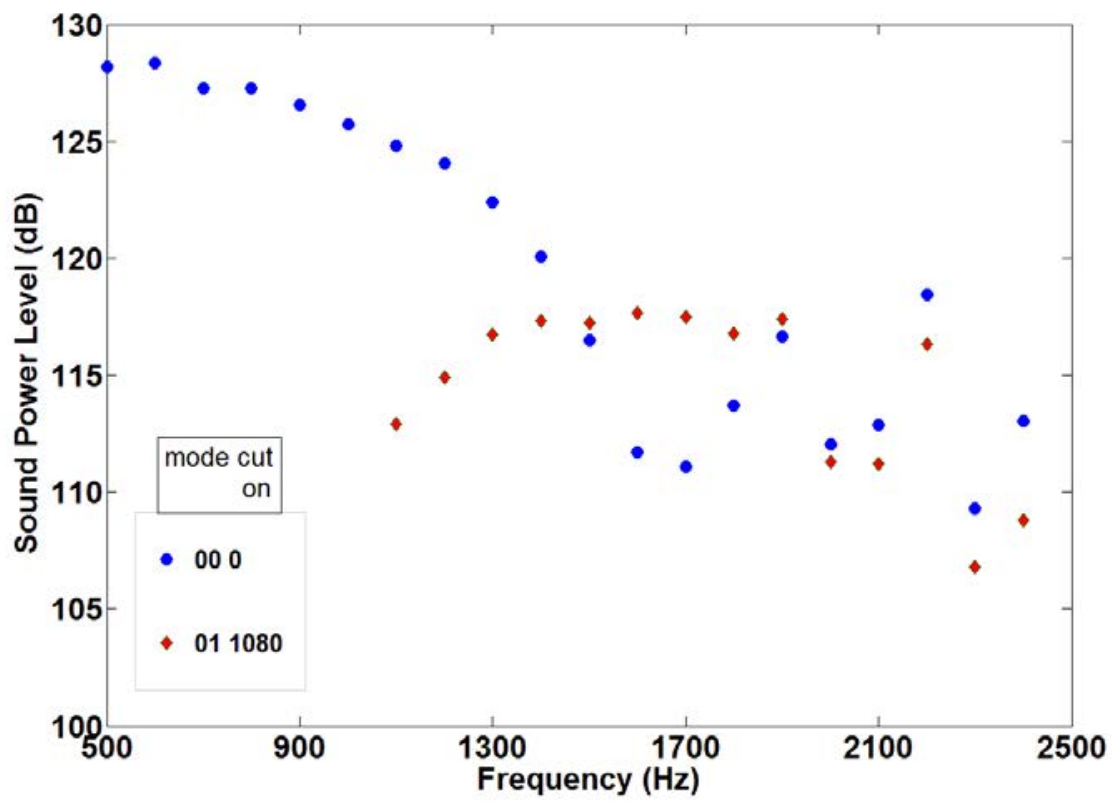

Figure 19. Mode distribution of sound power downstream of liner sample section in 'exhaust' orientation, 1D offset, asymmetric liner L04RE, for $(0,0)$ mode incident, Mach 0.275 .

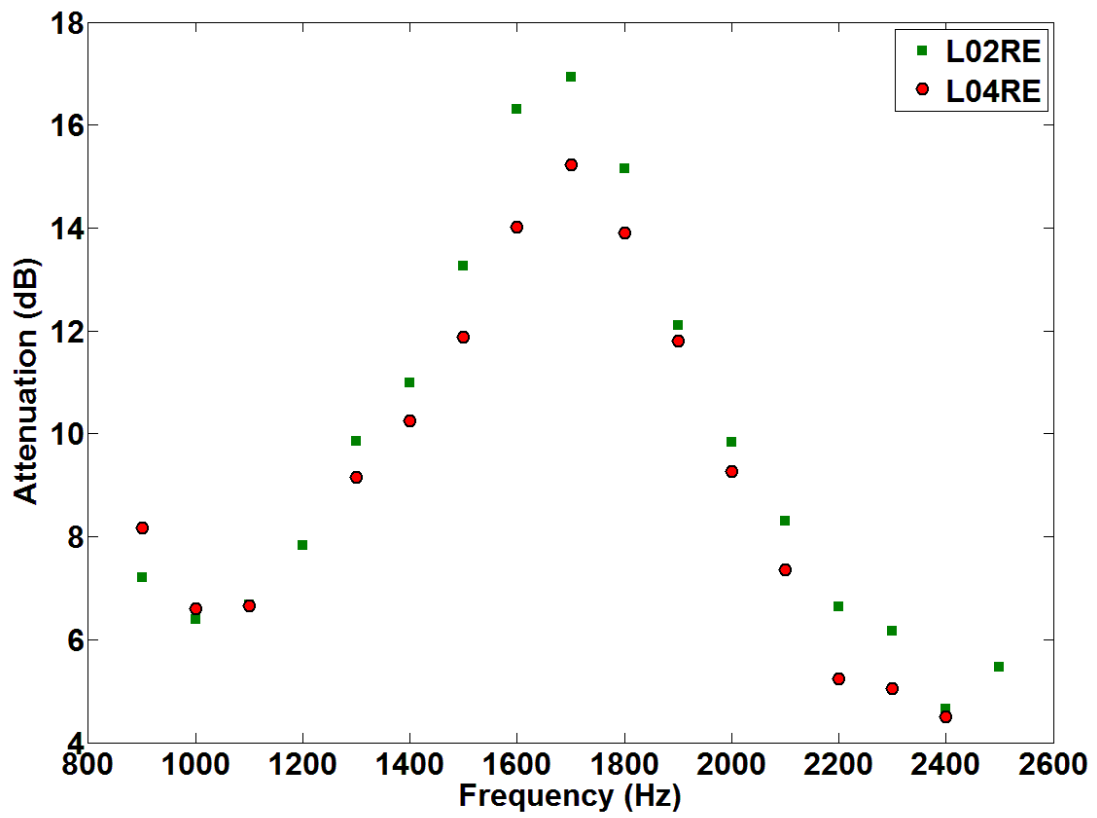

Figure 20. Overall attenuation of $(2,0)$ mode incident on asymmetric liner at Mach 0.275 in 'exhaust' orientation, comparing 0 offset (L02RE) to $1 D$ offset (L04RE).

\section{Summary}

The CDTR is designed to provide a test bed for evaluation of the acoustic performance of near-full scale liners at realistic flow conditions. The sound control system permits generation and isolation of user-selected modes 
in the duct to facilitate investigation of mode scatter by the liners. The CDTR has been used to investigate the effects of liner symmetry, flow direction, and flow path curvature on liner acoustic performance. The results reported in this paper show the effects of variation of these design or operating parameters on both the overall attenuation by the liner and the scatter of modal energy.

The results show that the intersection of the "Optimum" Impedance curve with the measured impedance is a good indicator of the frequency of peak attenuation, and in particular shows the change in peak frequency with configuration change.

The results show that, when one side of the duct is lined, energy scatters from 0 order horizontal modes to order 1 horizontal modes at the same vertical mode order, but only near the frequency of peak attenuation. The scatter decreases with increasing vertical order and it is less in the 'inlet' orientation than 'exhaust'. The asymmetric treatment scatters horizontal order 1 mode energy down to the less attenuated 0 order over more of the frequency range, and the scatter is stronger for 'inlet' than for 'exhaust'.

When both sides of the duct are lined, 0 horizontal mode energy scatters to the higher order 2 horizontal mode, but not very efficiently. The attenuation is so great that the sound leaving the liner is near the noise floor of the duct. The symmetric treatment scatters incident order 2 horizontal mode energy very efficiently to the lower order 0 .

Curvature is found not to have a significant effect on sound propagation, but the curve of the liners tested was designed not to be aggressive. A difference was noted for the case where the incident 0 order horizontal mode wave encounters a solid surface at the bend due to the offset. In this case the 0 order mode scatters into the horizontal order 1 mode to the detriment of noise reduction.

The liners investigated were not designed for optimum performance around any particular operating condition. However, the results obtained indicate how the mode distribution is affected by the duct configuration and how the mode distribution affects acoustic performance. If the source is known to generate noise predominantly in a specific mode, the liner design can be segmented such that part attenuates the target mode and the energy that is scattered goes into modes for which other segments of the liner are designed. Thus, the results indicate that the design can be manipulated to improve noise reduction or to provide equivalent noise reduction with less liner treatment. Plans are underway to modify the liners used in this study to evaluate the feasibility of segmented treatment to attenuate a $(0,0)$ mode and control mode scatter.

\section{Acknowledgements}

The authors are grateful for contributions made to the successful completion of this project by the laboratory technician staff and in particular Christal Kellam of NASA LaRC for experiment set-up and data collection. NASA's Subsonic Fixed Wing Project of the Fundamental Aeronautics Program funded this work.

\section{References}

1. Motsinger, R.E. and Kraft, R.E., "Design and Performance of Duct Acoustic Treatment", chapter 14, Aeroacoustics of Flight Vehicles, Theory and Practice, vol 2, Noise Control, NASA RP 1258, H.H. Hubbard, ed, 1991

2. Mani, R., Luedke, J, and Jones, M.G., "Improved Inlet Noise Attenuation by Alteration of Boundary Layer Profiles", proceedings of the Active 04, 2004 International Symposium of Active Control of Sound and Vibration, 2004

3. Fuller, C.R. and Bies, D.A., "Propagation Of Sound In A Curved Bend Containing A Curved Axial Partition", Journal of the Acoustical Society of America, volume 63, pp 681-686, 1978

4. Gerhold, C.H., Brown, M.C., Jones, M.G., Nark, D., and Howerton, B.M., "Configuration Effects On The Acoustic Performance Of A Duct Liner", AIAA paper 2008-2977, May, 2008

5. Chestnutt, D. and Lansing, D.C., "Survey of Inlet Noise Reduction Concepts for Gas Turbine Engines", NASA TM X-72801, 1976

6. $\quad$ Motsinger, R.E., Kraft, R.E., Zwick, J.W., Vukelich, S., Minner, G.L., and Baumeister, K.J., "Optimization of Suppression for 2-Element Treatment Liners in Turbomachinery Exhaust Ducts", NASA CR 134997, April, 1976 
7. Gerhold, C., Cabell, R, and Brown, M., "Development Of An Experimental Rig For Investigation Of Higher Order Modes In Ducts", AIAA paper 2006-2637, May, 2006

8. Gerhold, C.H., Brown, M.C., Jones, M.G., and Howerton, B.H., "Report on Recent Upgrades to the Curved Duct Test Rig at NASA Langley Research Center", AIAA paper 2011-2896, June, 2011

9. Jones, M. G., Parrott, T. L., and Watson, W. R., "Uncertainty and Sensitivity Analyses of a Two-Parameter Impedance Prediction Model", AIAA paper 2008-2928, May, 2008

10. Jones, M.G., Parrott, T.L., and Watson, W.R., "Comparison of Acoustic Impedance Eduction Techniques for Locally-Reacting Liners," AIAA paper 2003-3306, May, 2003

11. Cremer, L., "Theory Regarding The Attenuation Of Sound Transmitted By Air In A Rectangular Duct With An Absorbing Wall, And The Maximum Attenuation Constant", Acustica, vol 3, pp 249-263, 1953

12. Beranek, L.L., Noise and Vibration Control, chapter 15, McGraw-Hill Book Company, New York, NY, 1971

13. Kraft, R.E., "Theory And Measurement Of Acoustic Wave Propagation In Multi-Segmented Rectangular Flow Ducts", report number R77AEG585, General Electric Technical Information Series, Oct, 1977

14. Tester, B.J., "The Propagation and Attenuation of Sound in Lined Ducts Containing Uniform or 'Plug' Flow", JSV vol 28, no 2, pp 151-203, 1973

15. Gerhold, C.H., Jones, M.G., Brown, M.C., and Nark, D., "Advanced Computational And Experimental Techniques For Nacelle Liner Performance Evaluation”, AIAA paper 2009-3168, May, 2009 